and enthesitis), with no interaction effect between both habits. Smoking seems to be associated with predominantly upper limbs arthritis while alcohol intake seems to be associated with a predominantly oligo/mono articular involvement. Future studies are required including the influence of psoriasis and psoriatic arthritis in the relationship between alcohol and smoking and its association with peripheral manifestations. REFERENCES:

[1] Zhao S, Thong D, Duffield SJ, et al. Alcohol and disease activity in axial spondyloarthritis: a cross-sectional study. Rheumatol Int 2018. 38(3):375-381.

Table 1. Association between peripheral musculoskeletal manifestations and smoking and alcohol.

\begin{tabular}{|c|c|c|c|c|c|c|c|c|c|}
\hline & \multicolumn{3}{|c|}{$\begin{array}{l}\text { Peripheral joint disease } \\
\text { with objective signs in } \\
\text { the past }\end{array}$} & \multicolumn{3}{|c|}{$\begin{array}{l}\text { Peripheral enthesitis } \\
\text { with objective signs in } \\
\text { the past }\end{array}$} & \multicolumn{3}{|c|}{ Dactylitis in the past } \\
\hline & $\begin{array}{c}\text { Yes } \\
2292\end{array}$ & $\begin{array}{c}\text { No } \\
2169\end{array}$ & $\begin{array}{c}\text { OR } \\
(95 \% \mathrm{Cl})^{\star}\end{array}$ & $\begin{array}{l}\text { Yes } \\
765\end{array}$ & $\begin{array}{c}\text { No } \\
3696\end{array}$ & $\begin{array}{c}\text { OR } \\
(95 \% \mathrm{Cl})^{\star}\end{array}$ & $\begin{array}{l}\text { Yes } \\
685\end{array}$ & $\begin{array}{c}\text { No } \\
3776\end{array}$ & $\begin{array}{c}\text { OR } \\
(95 \% \mathrm{Cl})^{\star}\end{array}$ \\
\hline $\begin{array}{c}\text { Smoker } \\
\text { ever }\end{array}$ & $\begin{array}{c}887 \\
(38.7 \%)\end{array}$ & $\begin{array}{c}1013 \\
(46.7 \%)\end{array}$ & $\begin{array}{l}\text { OR } 0.72 \\
\begin{array}{l}(0.63- \\
0.82)\end{array}\end{array}$ & $\begin{array}{c}312 \\
(40.8 \%)\end{array}$ & $\begin{array}{c}1588 \\
(43.0 \%)\end{array}$ & $\begin{array}{l}\text { OR } 0.75 \\
\begin{array}{l}(0.63- \\
0.89)\end{array}\end{array}$ & $\begin{array}{c}277 \\
(40.4 \%)\end{array}$ & $\begin{array}{c}1623 \\
(43.0 \%)\end{array}$ & $\begin{array}{c}\text { OR } 0.89 \\
\begin{array}{c}(0.75- \\
1.06)\end{array}\end{array}$ \\
\hline $\begin{array}{c}\text { Alcohol } \\
\text { ever }\end{array}$ & $\begin{array}{c}929 \\
(40.4 \%)\end{array}$ & $\begin{array}{c}882 \\
(40.7 \%)\end{array}$ & $\begin{array}{l}\text { OR } 0.82 \\
(0.71- \\
0.94)\end{array}$ & $\begin{array}{c}276 \\
(36.1 \%)\end{array}$ & $\begin{array}{c}1535 \\
(41.5 \%)\end{array}$ & $\begin{array}{l}\text { OR } 0.69 \\
(0.57- \\
0.83)\end{array}$ & $\begin{array}{c}299 \\
(43.6 \%)\end{array}$ & $\begin{array}{c}1512 \\
(40.0 \%)\end{array}$ & $\begin{array}{c}\text { OR } 1.01 \\
(0.84- \\
1.22)\end{array}$ \\
\hline
\end{tabular}

*Mixed logistic regression using the country as a random effect.

Disclosure of Interests: None declared.

DOI: 10.1136/annrheumdis-2021-eular.1064

\section{POS0966 IDENTIFICATION OF PATIENTS AFFECTED WITH ANKYLOSING SPONDYLITIS AND INFLAMMATORY BOWEL DISEASE OVERLAP USING COLLAGEN BIOMARKERS}

S. Holm Nielsen ${ }^{1}$, A. Stahly ${ }^{2}$, E. H. Regner ${ }^{2}$, A. C. Bay-Jensen ${ }^{3}$, M. Karsdal ${ }^{4}$, K. A. Kuhn ${ }^{2} .{ }^{1}$ Nordic Bioscience \& Technical University of Denmark, ImmunoScience, Herlev, Denmark; ${ }^{2}$ University of Colorado Anschutz Medical Center, Department of Medicine, Division of Rheumatology, Aurora, United States of America; ${ }^{3}$ Nordic Bioscience, ImmunoScience, Herlev, Denmark; ${ }^{4}$ Nordic Bioscience, RnD, Herlev, Denmark

Background: Chronic inflammatory arthritis is a hallmark of Ankylosing Spondylitis (AS), where co-existence of inflammatory bowel disease, such as Crohn's Disease (CD) is prominent. The clinical overlap of $A S$ and $C D$ has raised the hypothesis that these conditions may have similar pathophysiological mechanisms. Both indications are characterized by an altered extracellular matrix turnover, where particularly collagens are remodeled.

Objectives: We investigated the association between biomarkers of collagen degradation in healthy controls and patients with $A S, C D$ and $A S / C D$ overlap, with the aim to investigate the biomarkers' ability to identify patients with $A S / C D$ overlap.

Methods: Patients with AS fulfilling ASAS criteria $(n=13)$, biopsy-proven $C D(n=14)$, subjects with $A S$ and $C D$ overlap $(n=10)$ and healthy controls $(n=11)$ undergoing standard of care colonoscopies were included in the study. The collagen degradation biomarkers measuring type III, IV, VI and X collagen (C3M, C4M, C6M and C10C, respectively) were measured in EDTA plasma samples from all subject groups. Biomarkers were measured by competitive ELISAs. Statistical analysis was performed using an ANCOVA adjusted for age, an AUROC analysis and spearman correlations. Results: The collagen biomarker C4M was significantly higher in patients with AS/CD overlap compared to AS, CD and HCs (all $p<0.0001$, Figure $1 A$ ). The blood levels of C4M in AS patients were significantly lower than $\mathrm{HC}(\mathrm{p}=0.0003)$, while $\mathrm{CD}$ also showed a lower level compared to $\mathrm{HC}$ though not significant $(p=0.0798)$. No difference was found between $\mathrm{AS}$ and $\mathrm{CD}$ alone. In an AUROC analysis, C4M showed a complete separation between the patients with $A S / C D$ overlap compared to $H C, A S$ and $C D$ with an $A U C=1.00 ; p=0.0001$. No differences were found between the patient groups for C3M, C6M and C10C (Figure 1, B-D). $91.3 \%$ of patients with AS, $92.8 \%$ of patients with $C D$ and $60 \%$ of patients with AS and IBD overlap were actively treated with TNF- $\alpha$ inhibitors, which may explain the suppression of the collagen degradation biomarker levels in AS, CD and AS/IBD overlap compared to healthy controls[1,2]. No correlations were found between the collagen biomarkers and CRP, BASDAI, SCCAI or HBI scores. Conclusion: Degradation of type IV collagen quantified by C4M showed a complete separation of patients with AS/IBD overlap, compared to $A S, C D$ and $\mathrm{HC}$ patients, which indicates an excessive collagen degradation and epithelial turnover. This biomarker could potentially be used to identify patients affected by both manifestations, and guide treatment decisions.

REFERENCES:

[1] van Haaften WT, Mortensen JH, Dige AK, Grønbæk H, Hvas CL, Bay-Jensen AC, et al. Serological Biomarkers of Tissue Turnover Identify Responders to
Anti-TNF Therapy in Crohn's Disease: A Pilot Study. Clin Transl Gastroenterol. 2020;11:e00217.

[2] Siebuhr AS, Bay-Jensen AC, Karsdal MA, Lories RJ, de Vlam K. CRP and a biomarker of type I collagen degradation, C1M, can differentiate anti-inflammatory treatment response in ankylosing spondylitis. Biomark Med. 2016;10:197-208.
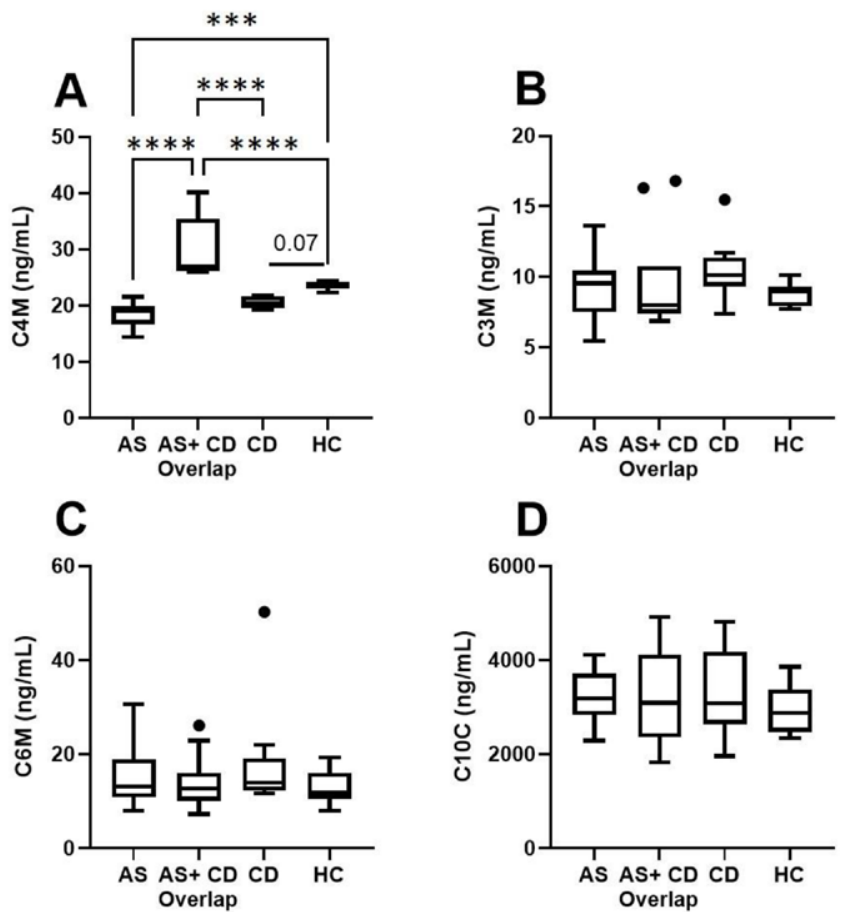

Figure 1. Levels of C4M (A), C3M (B), C6M (C) and C10C (D) in EDTA plasma from patient diagnosed with AS $(n=13), C D(n=14)$, AS and CD overlap $(n=10)$ and HC $(n=11)$. Graphs are presented as Tukey box plots. Statistical significance: ${ }^{\star \star \star \star} p<0.0001$.

Disclosure of Interests: Signe Holm Nielsen Employee of: Full time PostDoc at Nordic Bioscience and Technical University of Denmark, Andrew Stahly: None declared, Emilie H. Regner: None declared, Anne-Christine Bay-Jensen Shareholder of: Stocks at Nordic Bioscience, Employee of: Full-time employee at Nordic Bioscience, Morten Karsdal Shareholder of: Stocks at Nordic Bioscience, Employee of: Full-time employee at Nordic Bioscience, Kristine A. Kuhn: None declared. DOI: 10.1136/annrheumdis-2021-eular.1206

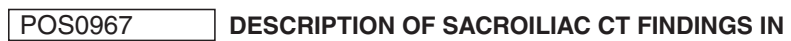 PATIENTS WITH ANKYLOSING SPONDYLITIS AGED OVER 50 YEARS: PRELIMINARY RESULTS OF THE CASIAGE STUDY}

O. Fakih ${ }^{1}$, M. Chouk ${ }^{1}$, C. Prati ${ }^{1,2}$, D. Wendling ${ }^{1,3}$, F. Verhoeven ${ }^{1,2},{ }^{1}$ Centre hospitalier régional universitaire de Besançon, Rhumatologie, Besançon, France; ${ }^{2}$ UFR Santé, Université de Franche-Comté, EA 4267 'PEPITE', Besançon, France; ${ }^{3}$ UFR Santé, Université de Franche-Comté, EA 4266 'EPILAB', Besançon, France

Background: Diagnosis of axial spondyloarthritis $(\mathrm{SpA})$ is nowadays commonly made with the help of pelvic radiography or MRI. However, there is an important inter-observer variability for radiographs, and MRI is subject to possible false positives, and is not the best modality for studying structural lesions. Conversely, pelvic CT has an excellent specificity and appears to be more effective than radiography for the diagnosis of SpA [1]. However, CT findings in patients over 50 years of age have not been studied.

Objectives: To describe sacroiliac ( $\mathrm{SI})$ joint $\mathrm{CT}$ characteristics in patients with ankylosing spondylitis (AS), aged 50 years or older.

Methods: An observational, cross sectional study was performed using medical records from Besançon University Hospital's rheumatology department which were screened to identify patients with AS. A search was then carried out for patients over 50 years old in the hospital's imaging archiving system to identify those who had benefited from a CT which included the SI joints in their entirety. Non-inclusion criteria were the existence of pelvic bone lesions and a history of pelvic radiotherapy. For each patient, CT was interpreted using a score previously used by Diekhoff et al. [2], dividing each SI joint into 12 regions, for each of which joint space narrowing (JSN), erosions, and sclerosis are assessed. For this study, we also observed the existence of 